\title{
A Review of MPPT Algorithms Employed in Wind Energy Conversion Systems
}

\author{
Ayushi Sachan*, Akhilesh Kumar Gupta and Paulson Samuel \\ Motilal Nehru National Institute of Technology Allahabad, India \\ E-mail: \{ayushisachan01; akhileshgupta08\}@gmail.com; paul@mnnit.ac.in \\ ${ }^{*}$ Correspending Author
}

Received 16 April 2017; Accepted 17 August 2017;

Publication 8 September 2017

\begin{abstract}
The depleting nature of fossil fuels and the environmental threats have resulted in the emergence of renewable energy sources (RESs) as alternative and accessible energy resources. Amongst various RESs, wind energy is one of the fastest growing distributed energy resources because of its zero-carbon emission and cost efficient generation. Although wind energy is plentiful, it is of intermittent nature, i.e., the wind speed is not constant throughout. So, the strategy followed is to harness maximum output power from this variable wind as when it is available, and various algorithms for maximum power operating point tracking (MPPT) have been proposed and implemented successfully. However, choosing an exact MPPT algorithm for a particular application requires a high degree of skill as each algorithm has its pros and cons. This paper presents a review of various MPPT algorithms suggested in the literature.
\end{abstract}

Keywords: WECS, MPPT, TSR, P\&O, ORB.

\section{Introduction}

The present and future energy crisis and depleting nature of conventional sources have led to an increased interest in power generation through nonconventional sources of energy. Renewables are the fastest-growing source of

Journal of Green Engineering, Vol. 6_4, 385-402.

doi: 10.13052/jge1904-4720.643

(c) 2017 River Publishers. All rights reserved. 
energy for electricity generation, with an average increase of $2.9 \%$ per year from 2012 to 2040 [1]. Now, renewable resources have become vital elements for electrification, and some of the primary sources among renewables are the wind, solar, tidal, biomass, etc. Among all renewable sources, wind energy is gaining more support due to its zero-carbon emission and its cost effectiveness, and it is the most rapidly growing means of distributed power generation. According to Global Wind Energy Council report, 54 GW of wind power was added in 2016, bringing total global installed capacity to nearly $487 \mathrm{GW}$. China, the US, Germany, India and France are the leading users of wind energy [2].

Since wind speed is highly unpredictable in nature and the output of wind energy conversion system (WECS) varies continuously with time. Thus, to achieve high efficiency, variable-speed wind energy conversion systems (VSWECS) like doubly-fed induction generator (DFIG) and permanent magnet synchronous generator (PMSG) based systems are preferred over fixed-speed WECS like squirrel cage induction generator based systems and maximum power point tracking (MPPT) algorithms are incorporated for maximizing energy harvest. However, choosing an appropriate MPPT algorithm for a particular case requires sufficient proficiency with each because each algorithm has its own merits and demerits. For this reason, a review of those algorithms is essential. The article is divided into four sections including the introductory section. These sections are as follows: the basic idea of maximum power tracking is given in Section 2. The classification of various MPPT algorithms is made in Section 3, and Section 4 provides the conclusion.

\section{Wind Energy Concept}

The mechanical power produced by a wind turbine is given by:

$$
P=\frac{1}{2} \rho \pi R^{2} C_{P}(\lambda, \beta) v_{w}^{3}
$$

Where $\rho$ is the air density $\left(\mathrm{kg} / \mathrm{m}^{3}\right), \mathrm{R}$ is the radius of the turbine blade $(\mathrm{m})$, $v_{w}$ is the wind velocity $(\mathrm{m} / \mathrm{s}), C_{p}$ is the turbine power coefficient which is a measure of turbine power conversion efficiency and is a function of tip speed ratio $(\lambda)$ and blade pitch angle $(\beta)$.

Tip speed ratio is defined as the ratio of the blade tip speed to the wind velocity striking the blades and can be expressed as [3]

$$
\lambda=\frac{\omega R}{v_{w}}
$$




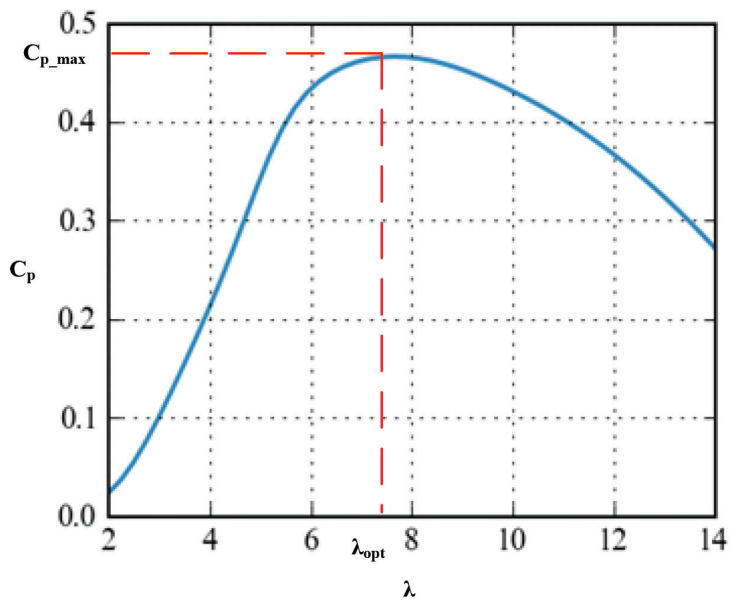

Figure $1 C_{p}-\lambda$ curve.

where $\omega$ is the mechanical angular speed of the turbine ( $\mathrm{rad} / \mathrm{s})$.

To obtain the maximum power, $C_{p}$ should achieve its maximum value for a given wind turbine. It is apparent from the $C_{p}-\lambda$ curve shown in Figure 1 that the maximum $C_{p}\left(C_{p_{-} \max }\right)$ occur at an optimum value of tip speed ratio $\left(\lambda_{\text {opt }}\right)$.

The $C_{p}-v_{w}$ characteristics of an Enercon E40 $2.3 \mathrm{~kW}$ gearless, variable speed, variable pitch control turbine data [4] is plotted in Figure 2 as power coefficient $C_{p}$ versus $v_{w}$ and $P$ versus $v_{w}$. The maximum value of power coefficient for $\mathrm{E} 40$ is 0.5 . At this point, the wind turbine is getting its rated power at the wind speed of $16 \mathrm{~m} / \mathrm{sec}$ (shown as a green line in Figure 2(b)) with power coefficient $C_{p}=0.23$ (shown in Figure 2(a)). The MPPT algorithm is applied to maximise the extracted wind energy by maximisation of the power coefficients below the rated speed. The MPPT curve is shown by red line which depicts that the wind turbine is now abstracting the maximum power at $13 \mathrm{~m} / \mathrm{sec}$ wind speed.

\section{MPPT Classifications}

The two broad classes of MPPT techniques used in wind energy conversion systems are 1) sensor-based methods [5-10] and 2) sensorless techniques [11-14]. Sensor based topologies use some mechanical sensors like anemometer for wind speed measurement and tacho-generator for rotor speed measurements whereas the later one makes use of electrical sensors for 


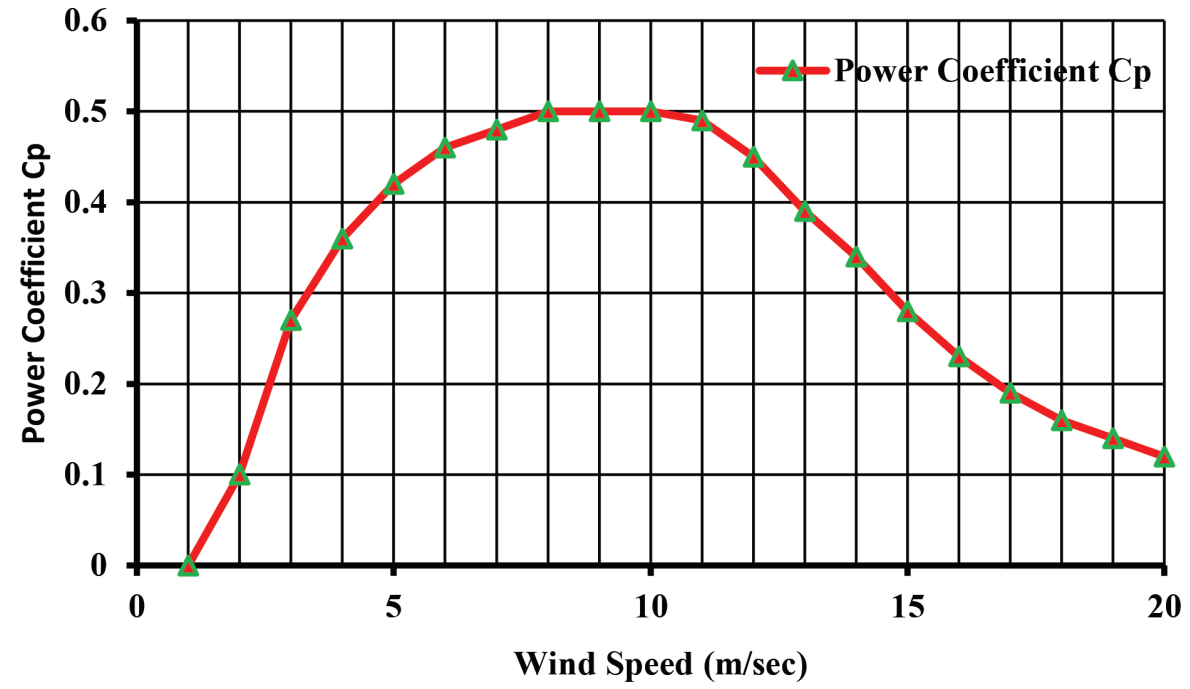

(a)

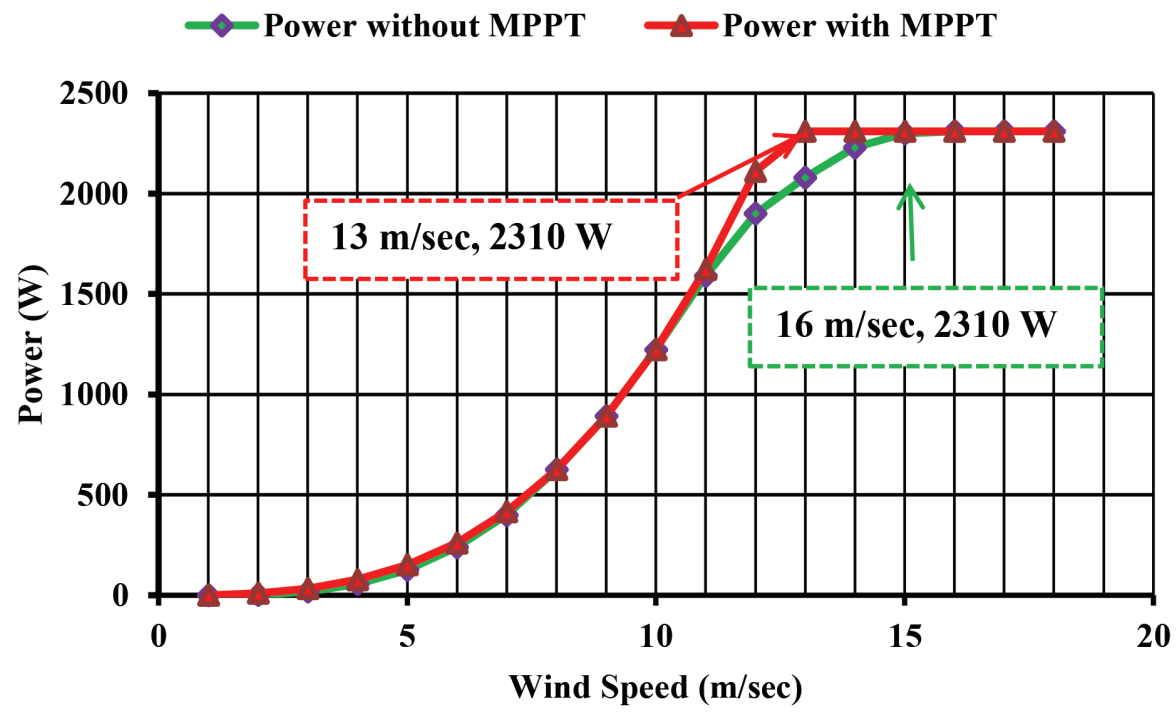

(b)

Figure 2 The characteristics of an Enercon E40 $2.3 \mathrm{~kW}$ gearless, variable speed, variable pitch control turbine. Curve (a) $C_{p}-v_{w}$ Curve (b) $P-v_{w}$ Curve. 


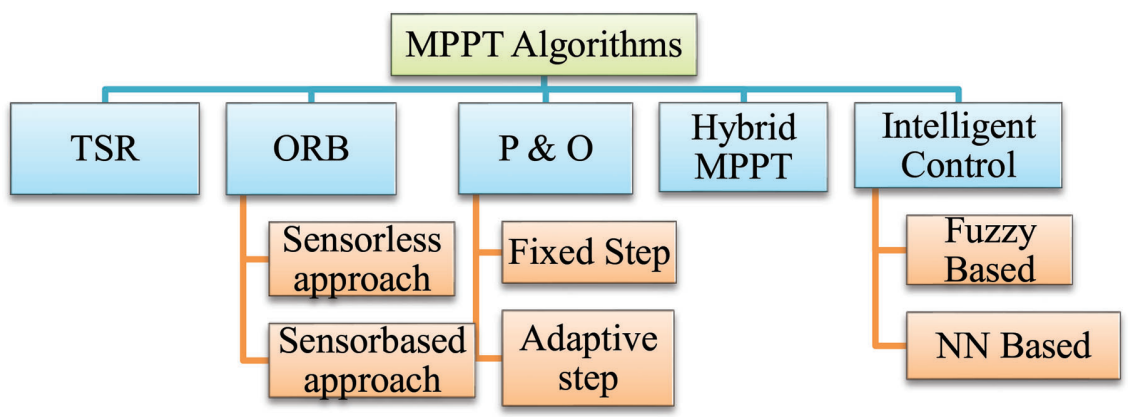

Figure 3 Classification of MPPT algorithms.

voltage, current or power sensing. An electromechanical generator generates the voltage roughly proportional to speed. With precise construction and design, it may produce particular voltage and may act as a speed measurement device for a ceratin range of speed. This type of generator is termed as tachogenerator. The polarity of the voltage generated by tacho-generator indicates the direction of rotation.

Other way of classification of MPPT techniques is shown in Figure 3. Different MPPT techniques employed in VSWECS are classified as 1) Tipspeed ratio (TSR) control, 2) Optimum relationship based (ORB) control, 3) Perturbation and observation ( $\mathrm{P} \& \mathrm{O})$ control, 4) Hybrid control and 5) Intelligent control techniques like fuzzy logic control [15], neural network control [16], etc.

All of the above MPPT algorithms are discussed in detail in the following sections.

\subsection{Tip Speed Ratio Control}

In this algorithm, TSR (defined in Equation (2)) is kept at an optimum value to extract maximum power from the wind by regulating generator rotational speed on the fluctuation in wind velocity. The optimum TSR as shown in Figure 4 is set as a reference value which can be determined experimentally or theoretically $[17,19]$. This method is straightforward and fast because it measures wind speed directly. It extracts more power from rapidly varying wind as it depicts non-minimum phase characteristics with higher gain at higher frequencies [17]. On the other hand, it requires anemometer for wind measurement, so continuous and precise measurement of wind speed is not possible since wind speed is not constant throughout the blade swept area. 


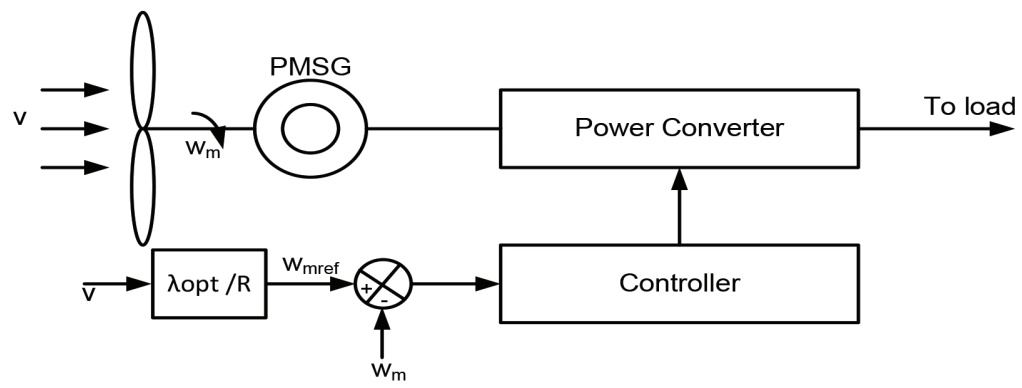

Figure 4 Tip Speed Ratio control.

Installation of an array of anemometers can be a solution for accurate wind measurement, but it increases the cost of the system. Also, the TSR MPPT algorithm generates fluctuations in generator output power.

\subsection{Optimal Relationship Based (ORB) Algorithm}

This algorithm relies on drawing optimum relationships between different parameters of wind energy conversion system like wind velocity, output mechanical power, rectified dc voltage, rectified current, output electrical power, etc. Such techniques utilize lookup table or predefined curves to track the MPP. It is also termed as power signal feedback (PSF) control. Most of the ORB techniques are based on the field test to obtain the data for fast and accurate MPPT tracking. Further, ORB methods are classified as sensor based and sensor-less approaches.

\subsubsection{Sensor based approach}

These techniques require some mechanical sensors to obtain the data. In [20-23], the relationship between electromagnetic torque and rotor speed (optimum torque method) is used. The operating principle of this method is to adjust the generator torque (Figure 5) according to the maximum value of a reference torque curve. The optimal value of torque is obtained at $\lambda=\lambda_{\text {opt }}$ and $C_{p}=C_{p_{-} \max }$ is given by:

$$
\begin{aligned}
T_{m_{o p t}} & =\frac{1}{2} \rho \pi R^{5} \frac{C_{p \_ \text {max }}}{\lambda_{o p t}^{3}} \omega_{m}^{2} \\
T_{m_{\text {opt }}} & =k_{\text {opt }} \omega_{m}^{2}
\end{aligned}
$$




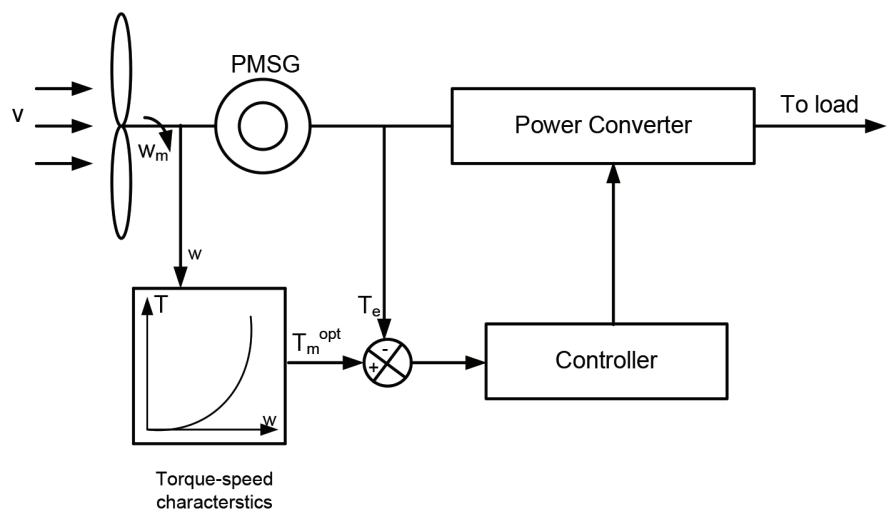

Figure 5 Optimum torque approach.

The predefined power versus rotor speed curve or look up table of the wind turbine is used to track the MPP in power signal feedback (PSF) (Figure 6) method to determine the maximum power at optimum rotor speed $[24,25]$. It works on the same principle as that of optimal torque algorithm. Here instead of torque-speed characteristic, power speed characteristic is used. The maximum power can be obtained either using the expression of turbine output power or using a pre-obtained turbine power-speed curve through simulation or experimental result. The following expression gives the maximum power corresponding to optimum generator speed:

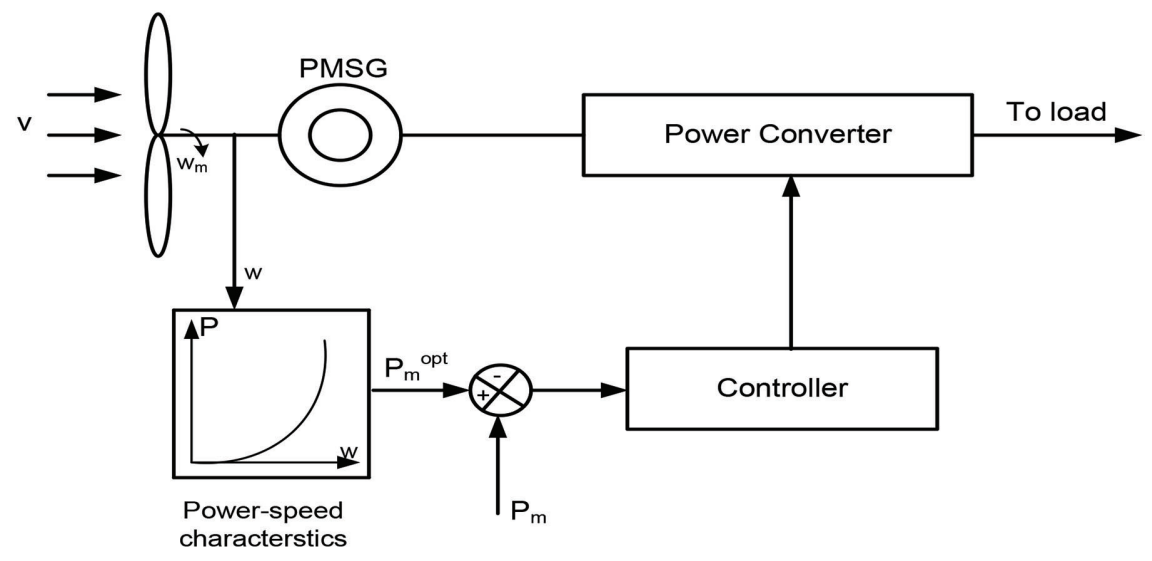

Figure 6 Power signal feedback approach. 


$$
P_{\text {opt }}=\pi R^{5} \rho C_{p_{-} \max } \omega_{\text {opt }}^{3} / 2 \lambda_{\text {opt }}^{3}=k_{\text {opt }} \omega_{\text {opt }}^{3}
$$

The major drawback of these methods is that they need mechanical sensors which increase the cost and reduce the reliability of the system.

\subsubsection{Sensor-less approach}

In WECS configuration with an uncontrolled rectifier, the relationship between power versus rectified voltage [26] or rectified dc voltage and rectified current [27] are used to track the MPP. Both these methods require only electrical sensors and remove the need for mechanical sensors.

The ORB algorithm is a straightforward approach with an excellent dynamic response. One of its limitations is that it requires prior knowledge of system parameters which are highly dependent upon the ageing effect and can vary in physical applications from one system to another.

In [28], an intermediate variable $\beta$ is created as a function of power and shaft speed and MPPT is tracked by keeping this variable constant irrespective of mechanical specifications.

\subsection{Hill Climb Search Method}

The HCS is also called perturbation and observation $(\mathrm{P} \& \mathrm{O})$ since it observes the perturbation in power and according to that it provides the corrections in the particular parameter like duty cycle of the DC-DC converter to control the dc voltage or to regulate current [29-31] in order to adjust the rotor speed and track the MPP. This method is based on perturbing control variable in arbitrary small steps, and the next perturbation is decided on observing the changes in power curve due to preceding perturbation. $\mathrm{P} \& \mathrm{O}$ approach is a widely used MPPT algorithm because of its simplicity and absence of mechanical speed sensor or anemometer for implementation.

This method suffers from following two drawbacks: sluggish response especially for low step size and inefficient operation under rapid wind variations [32]. A large oscillation will appear around the MPP if the selected step size is large. However, this problem can be eradicated using adaptive step size depending upon scaled measure of power slope with perturbing variable as proposed in [33] to make a balance between tracking speed and control efficiency. Still, the problem of misleading direction in rapidly varying wind remains. Authors in [34] proposed to modify $\mathrm{P} \& \mathrm{O}$ approach to suppress the above problem by two modes of operation: 1) The conventional $\mathrm{P} \& \mathrm{O}$ approach for slower wind speed and 2) a prediction mode based capacitor voltage slope 


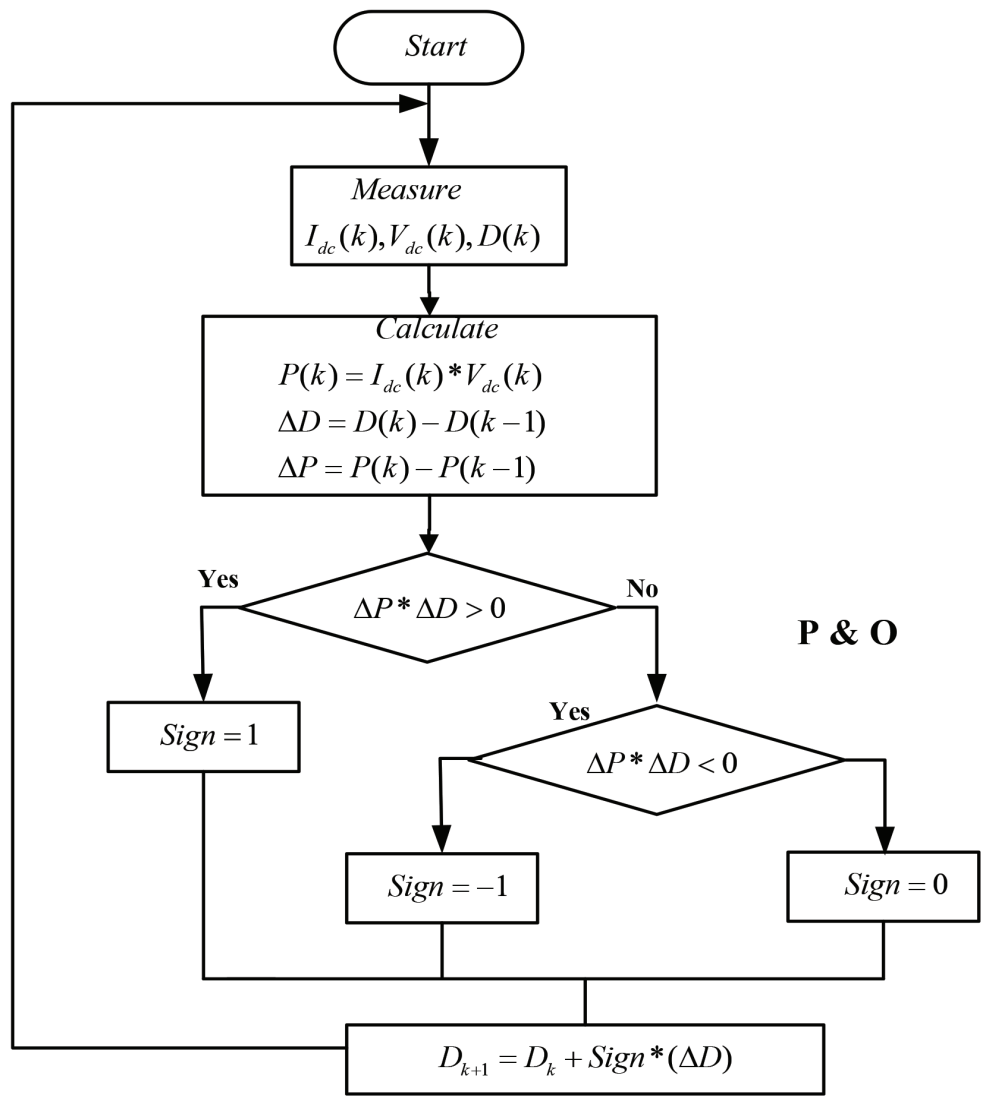

Figure 7 Flow chart of Perturbation and Observation (P\&O) algorithm.

for rapidly varying wind. The rectified current is selected as the perturbing variable. A flow chart of the $\mathrm{P} \& \mathrm{O}$ algorithm is shown in Figure 7.

\subsection{Hybrid MPPT Algorithm}

A hybrid method (flow chart is shown in Figure 8) is the combination of two approaches that overcome the drawbacks of one method by utilizing the advantages of the second one. An example of these methods was proposed by authors [35], where the ORB method was merged with $\mathrm{P} \& \mathrm{O}$ to solve the two problems associated with conventional $\mathrm{P} \& \mathrm{O}$ that are speed efficiency trade-off and wrong directionality under rapid wind change [34]. Further, authors in [36] proposed hybrid algorithm by combining the attributes of 


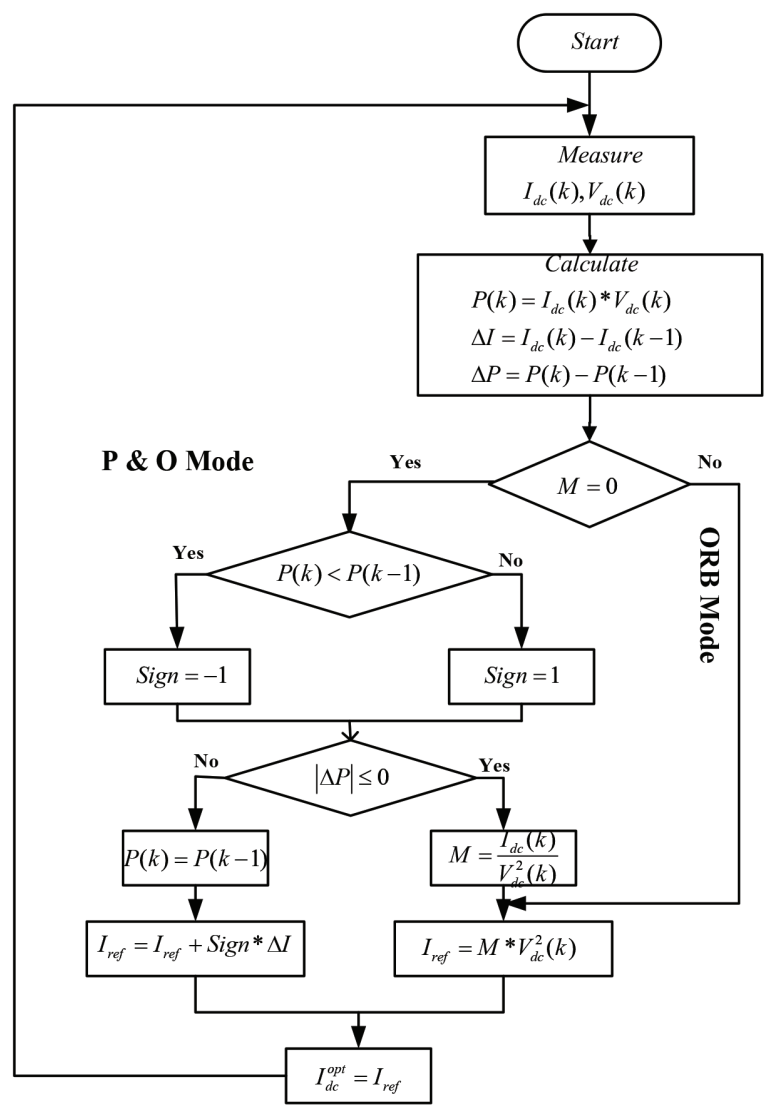

Figure 8 Flow chart of hybrid MPPT algorithm.

ORB and $\mathrm{P} \& \mathrm{O}$ methods to mitigate the limitations of both algorithms. The author in [37] proposed the so-called one power point (OPP) method in which a relationship between the rectified voltage and inductor current is developed by the knowledge of maximum power status for one local wind speed. Further, there is one coefficient in the developed equation. The wind turbine design and power coefficient drop are not considered in this paper. Another example was the combining of PSF control and HCS in [38] to develop a sensor-less and flexible method that applies to all wind turbine levels. The main drawback with these algorithms is that most of these algorithms need $\mathrm{P} \& \mathrm{O}$ or any other algorithms to develop the relationship. The performance of such algorithm deteriorates with the age of the system. 


\subsection{Other Intelligent Control Methods}

Neural network and fuzzy logic based control are used for complex nonlinear systems. Therefore, these intelligent control approaches are frequently used to represent complex plants and construct advanced controllers [39]. The fuzzy logic controller (FLC) does not require any mathematical modelling and instead its operation is based on a set of rules derived from the system behaviour. The rules are designed such that the controller always traces maximum power point without any knowledge of systems parameters, wind turbine characteristics or wind speed changes. Thus, FLC is a suitable tool for small WECS. Some other notable advantages of the fuzzy logic controller are its simplicity, robustness and computational speed [40]. V Galdi et al. [41, 42] present a data driven design methodology able to generate a Takagi-Sugeno-Kang (TSK) fuzzy based model for the MPPT operation.

Artificial Neural Network (ANN) based controller is a fast and reliable option over classical controllers for maximum power extraction from the available kinetic energy of wind. Pitch angle control of wind turbine to gain better performance in maximum power extraction and prediction of accurate wind speed and direction are major working areas for ANN controller. Ro et al. [43] have designed a neural network (NN) pitch controller of a grid connected wind turbine system for harvesting maximum power from available wind and proved that its performance is superior to conventional controllers. Li et al. [44] used a small WECS and applied neural network principles for wind speed estimation and robust control of maximum wind power extraction. Can et al. [45] proposed an intelligent MPPT control scheme which utilizes wind turbine dynamics response and short term wind speed prediction for two time intervals to compute the optimal control command. This method harvest more power for higher wind speed as well as increase overall wind power. Zhang et al. [46] proposed an improved adaptive torque gain (IATG) approach to determine the optimal gain coefficient to extract maximum power. This method overcome the drawback of ageing effect in decreased torque gain (DTG) and direction misleading problem with the adaptive torque gain (ATG) in rapidly changing wind speed.

Chun et al. [47] proposed reinforcement learning (RL) MPPT which is basically established on ANN. In this algorithm, ANNs and Q-learning method together first memorizes the optimal relationship between the rotor speed and electrical power output of the PMSG for MPPT operation. Once the MPP is acquired the algorithm is shifted from the online RL to the ORB based online MPPT. This procedure of online RL can be reactivated when there is 
Table 1 Comparison of different MPPT algorithms

\begin{tabular}{|c|c|c|c|c|c|}
\hline \multirow{2}{*}{\multicolumn{2}{|c|}{ MPPT Algorithm }} & Tracking & & Prior & \\
\hline & & Speed & Complexity & Knowledge & Application \\
\hline \multicolumn{2}{|c|}{ TSR Control } & Fast & Low & $\begin{array}{l}\text { Not } \\
\text { required }\end{array}$ & $\begin{array}{l}\text { Suitable for } \\
\text { medium } \\
\text { capacity WECS } \\
\text { with rapidly } \\
\text { varying wind } \\
\text { speed region } \\
\end{array}$ \\
\hline \multirow[t]{2}{*}{$\begin{array}{l}\text { ORB } \\
\text { Control }\end{array}$} & $\begin{array}{l}\text { OT \& PSF } \\
\text { Control }\end{array}$ & Fast & Low & Required & $\begin{array}{l}\text { Huge Capacity } \\
\text { WECS }\end{array}$ \\
\hline & $\begin{array}{l}\text { Relationship } \\
\text { between } \\
\text { voltage, } \\
\text { current, power } \\
\text { etc. based }\end{array}$ & Medium & Low & $\begin{array}{l}\text { Not } \\
\text { required }\end{array}$ & $\begin{array}{l}\text { Huge Capacity } \\
\text { WECS with } \\
\text { moderate wind } \\
\text { speed variation } \\
\text { region }\end{array}$ \\
\hline \multicolumn{2}{|c|}{ HCS or P\&O Control } & Slow & Low & $\begin{array}{l}\text { Not } \\
\text { required }\end{array}$ & $\begin{array}{l}\text { Suitable for low } \\
\text { cost and small } \\
\text { capacity WECS }\end{array}$ \\
\hline \multicolumn{2}{|c|}{ Hybrid Control } & Fast & Medium & $\begin{array}{l}\text { Not } \\
\text { required }\end{array}$ & $\begin{array}{l}\text { Huge Capacity } \\
\text { WECS }\end{array}$ \\
\hline \multicolumn{2}{|c|}{$\begin{array}{l}\text { Intelligent control } \\
\text { Like Fuzzy and } \\
\text { ANN based control }\end{array}$} & Medium & High & Required & $\begin{array}{l}\text { Suitable for } \\
\text { large scale } \\
\text { WECS }\end{array}$ \\
\hline
\end{tabular}

any digression from the already learned optimal relation and thus improves the system efficiency. The comparisons of all above methods discussed are tabulated in Table 1 .

\section{Conclusion}

Maximum power point tracking techniques are incorporated in WECS to make the energy extraction better and converge faster. A comprehensive review of various MPPT algorithms has been presented in the paper. These methods can be broadly classified into five categories each of them having their advantages and disadvantages. The direct power measurement techniques which include TSR, OTC, and PSF are simple to implement and give a fast response, but their dependence on wind turbine characteristics makes them inflexible. HCS and ORB algorithms come under sensorless methods and are cheaper and more reliable as they don't require any mechanical sensors, but they cannot track the exact MPP under rapid wind fluctuations. The hybrid algorithms are 
more accurate, robust and are advantageous than the above two categories of methods. Thus, a knowledge of all the techniques is necessary to design the best MPPT algorithm for a particular type of WECS.

\section{References}

[1] U.S. Energy Information Administration (2016). International Energy Outlook. Washington, DC: U.S. Energy Information Administration.

[2] GWEC (2016). Global Wind 2016 Report. Washington, DC: Global Wind Energy Council (GWEC).

[3] Bansal, D., and Pandey, K. (2016). "Blade pitch angle and tip speed ratio control schemes for constant power generation of WECS," in Proceedings of 2016 IEEE 1st International Conference on Power Electronics, Intelligent Control and Energy Systems (ICPEICES), Delhi, 1-6.

[4] Enercon. Wind Turbine: Product Review. Aurich; Enercon.

[5] Lin, W.-M., Hong, C.-M., Cheng, F. S., and Lu, K. H. (2011). "MPPT control strategy for wind energy conversion system based on RBF network," in Proceedings of the IEEE 2011 Energy Technologies, Cleveland, $\mathrm{OH}, 1-6$.

[6] Datta, R., and Ranganathan, V. T. (2003). "A method of tracking the peak power points for a variable speed wind energy conversion system. IEEE Trans. Energy Convers. 18, 163-168.

[7] Raju, A. B., Fernandes, B. G., and Chatterjee, K. (2004). "A UPF power conditioner with maximum power point tracker for grid connected variable speed wind energy conversion system," in Proceedings of the First International Conference on Power Electronics and Applications, Hong Kong, 107-112.

[8] Wang, Q., and Chang, L. (2004). An intelligent maximum power extraction algorithm for inverter based variable speed wind turbine systems. IEEE Trans. Power Electron. 19, 1242-1249.

[9] Hui, J., and Bakhshai, A. (2008). "Adaptive algorithm for fast maximum power point tracking in wind energy systems," in Proceedings of the IEEE Industrial Electronics Conference, Orlando, FL, 2119-2124.

[10] Heydari, M., and Smedley, K. (2015). "Comparison of maximum power point tracking methods for medium to high power wind energy systems," in Proceedings of 2015 20th Conference on Electrical Power Distribution Networks Conference (EPDC), Zahedan, 184-189. 
[11] Dalala, Z. M., Zahid, Z. U., Yu, W., Cho, Y., and Lai, J. S. (2013). Design and analysis of an MPPT technique for small-scale wind energy conversion systems. IEEE Trans. Energy Convers. 28, 756-767.

[12] Singh, M., and Chandra, A. (2011). Application of adaptive networkbased fuzzy inference system for sensorless control of PMSG-based wind turbine with nonlinear load-compensation capabilities. IEEE Trans. Power Electron. 26, 165-175.

[13] Morimoto, S., Nakayama, H., Sanada, M., and Takeda, Y. (2005). Sensorless output maximization control for variable-speed wind generation system using IPMSG. IEEE Trans. Ind. Appl. 41, 60-67.

[14] Raza, K. S. M., Goto, H., Guo, H., and Ichinokura, O. (2007). "Maximum power point tracking control, and voltage regulation of a DC grid-tied wind energy conversion system based on a novel permanent magnet reluctance generator," in Proceedings of the International Conference on Electrical Machines and Systems ICEMS, Seoul, 1533-1538.

[15] Simoes, M. G., Bose, B. K., and Spiegel, R. J. (1997). Fuzzy logic based intelligent control of a variable speed cage machine wind generation system. IEEE Trans. Power Electron. 12, 87-95.

[16] Chedid, R., Mrad, F., and Basma, M. (1999). Intelligent control of class of wind energy conversion systems. IEEE Trans. Energy Convers. 14, 1597-1604.

[17] Nasiri, M., Milimonfared, J., and Fathi, S. H. (2014). Modeling, analysis and comparison of TSR and OTC methods for MPPT and power smoothing in permanent magnet synchronous generator-based wind turbines. Elsevier J. Energy Conver. Manag. 86, 892-900.

[18] Johnson, K. E., Pao, L. Y., Balas, M. J., and Fingersh, L. J. (2006). Control of variable-speed wind turbines: standard and adaptive techniques for maximizing energy capture. IEEE Control Syst. 26, 70-81.

[19] Balasundar, C., Sudharshanan, S., and Elakkiyavendan, R. (2015). Design of an optimal tip speed ratio control MPPT algorithm for standalone WECS. Int. J. Res. Appl. Sci. Eng. Technol. 3, 442-450.

[20] Bouscayrol, A., Guillaud, X., Delarue, P., and Lemaire-Semail, B. (2009). Energetic macroscopic representation and inversion-based control illustrated on a wind-energy-conversion system using hardware-in-the-loop simulation. IEEE Trans. Ind. Electron. 56, 4826-4835.

[21] Ibarra, E., Kortabarria, I., Andreu, J., Martinez de Alegria, I., Martin, J., and Ibanez, P. (2012). Improvement of the design process of matrix converter platforms using the switching state matrix averaging simulation method. IEEE Trans. Ind. Electron. 59, 220-234. 
[22] Haque, M. E., Negnevitsky, M., and Muttaqi, K. M. (2010). A novel control strategy for a variable-speed wind turbine with a permanentmagnet synchronous generator. IEEE Trans. Ind. Appl. 46, 331-339.

[23] Morimoto, S., Kato, H., Sanada, M., and Takeda, Y. (2006). Output maximization control for wind generation system with interior permanent magnet synchronous generator," in Proceedings of the 4lth Conference Record IEEE IAS Annual Meeting, Tampa, Vol. 1, 503-510.

[24] Mahdavian, M., Wattanapongsakorn, N., Shahgholian, G., Mozafarpoor, S. H., Janghorbani, M., and Shariatmadar, S. M. (2014). Maximum power point tracking in wind energy conversion systems using tracking control system based on fuzzy controller," in Proceedings of 2014 11th International Conference on Electrical Engineering/Electronics, Computer, Telecommunications and Information Technology (ECTI-CON), Nakhon Ratchasima.

[25] Chien-Hung, L., and Yuan-Yih, H. (2011). Effect of rotor excitation voltage on steady-state stability and maximum output power of a doubly fed induction generator. IEEE Trans. Ind. Electron. 58, 1096-1109.

[26] Tan, K., and Islam, S. (2004). Optimum control strategies in energy conversion of PMSG wind turbine system without mechanical sensors. IEEE Trans. Energy Convers. 19, 392-399.

[27] Rahim, A. H. M. A. (2014). "Optimum relation based maximum power point tracking of a PMSG wind generator through converter controls," in Proceedings of the 7th IET International Conference on Power Electronics, Machines and Drives (PEMD 2014), Manchester, 1-6.

[28] Agarwal, V., Aggarwal, R. K., Patidar, P., and Patki, C. (2010). A novel scheme for rapid tracking of maximum power point in wind energy generation systems. IEEE Trans. Energy Convers. 25, 228-236.

[29] Koutroulis, E. and Kalaitzakis, K. (2006). Design of a maximum power tracking system for wind-energy-conversion applications. IEEE Trans. Ind. Electron. 53, 486-494.

[30] Patsios, C., Chaniotis, A., Rotas, M., Kladas, A. G. (2009). “A comparison of maximum power-point tracking control techniques for low-power variable-speed wind generators," Proceedings of the 8th International Symposium Advanced Electromechanical Motion System Electron Drives Jt Symposium, San Diego, CA, 1-3.

[31] Liu, C., Chau, K. T., and Zhang, X. (2010). An efficient windphotovoltaic hybrid generation system using doubly excited permanentmagnet brushless machine. IEEE Trans. Ind. Electron., 57, 831-839. 
[32] Kazmi, S. M. R., Goto, H., Hai-Jiao, G., and Ichinokura, O. (2011). A novel algorithm for fast and efficient speed-sensorless maximum power point tracking in wind energy conversion systems. IEEE Trans. Ind. Electron. 58, 29-36.

[33] Femia, N., Petrone, G., Spagnuolo, G., and Vitelli, M. (2005). Optimization of perturb and observe maximum power point tracking method. IEEE Trans. Power Electron. 20, 963-973.

[34] Dalala, Z. M., Zahid, Z. U., Yu, W., Cho, Y and Lai, J. S. (2013). Design and Analysis of an MPPT technique for small-scale wind energy conversion systems," IEEE Trans. Energy Convers. 28, 3.

[35] Xia, Y., Ahmed, K. H., and Williams, B. W. (2011). A new maximum power point tracking technique for permanent magnet synchronous generator based wind energy conversion system. IEEE Trans. Power Electron. 26, 3609-3620.

[36] Abdullah, M. A., Yatim, A. H. M., Tan, C. W. (2014). "An online optimum-relation-based maximum power point tracking algorithm for wind energy conversion system," Australasian Universities Power Engineering Conference (AUPEC), Perth.

[37] Zhang, H. B., Fletcher, J., Greeves, N., Finney, S. J., and Williams, B. W. "One-power-point operation for variable speed wind/tidal stream turbines with synchronous generators," IET Renew. Power Gener. 5, 99-108.

[38] Xia, Y., Ahmed, K. H., Williams, B. W. (2011). A new maximum power point tracking technique for permanent magnet synchronous generator based wind energy conversion system. IEEE Trans Power Electron. 26, 3609-3620.

[39] Petrila, D., Blaabjerg, F., Muntean, N., and Lascu, C. (2012). Fuzzy logic based MPPT controller for a small wind turbine system. Proceedings of the 13th International Conference on Optimization of Electrical and Electronic Equipment (OPTIM), Brasov, 993-999.

[40] Simoes, M. G., and Bose, B. K. (1997). Design and performance evaluation of fuzzy-logic-based variable-speed wind generation system. IEEE Trans. Ind. Appl. 33, 956-965.

[41] Galdi, V., Piccolo, A., and Siano, P. (2008). Designing an adaptive fuzzy controller for maximum wind energy extraction. IEEE Trans. Energy Convers. 23, 559-569.

[42] Galdi, V., Piccolo, A., Siano, P. (2009). Exploiting maximum energy from variable speed wind power generation systems by using an adaptive Takagi-Sugeno-Kang fuzzy model. Energy Convers. Manage. 50, 413-421. 
[43] Kyoungsoo, R., Han-ho, C., (2005). Application of neural network controller for maximum power extraction of a grid-connected wind turbine system. Elect. Eng. 88, 45-53.

[44] Li, H., Shi, K. L., and McLaren, P. G. (2005). Neural-network-based sensorless maximum wind energy capture with compensated power coefficient. IEEE Trans. Ind. Appl. 41, 6, 1548-1556.

[45] Huang, C., Li, F., Jin, Z. (2015). Maximum power point tracking trategy for large-scale wind generation systems considering wind turbine dynamics. IEEE Trans. Ind. Electron. 62, 4.

[46] Zhang, X., Huang, C., Hao, S., Chen, F., Zhai, J. (2016). An improved adaptive-torque-gain MPPT control for direct-driven PMSG wind turbines considering wind farm turbulences. Energies 9, 977.

[47] Wei, C., Zhang, Z., and Qu, L. (2016). An adaptive network-based reinforcement learning method for MPPT control of PMSG wind energy conversion systems. IEEE Trans. Power Electron. 31, 11.

\section{Biographies}

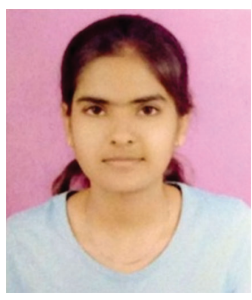

Ayushi Sachan received her B.E. degree in Electrical Engineering from Jabalpur Engineering College, Jabalpur, India, in 2014 and M.Tech. degree from Motilal Nehru National Institute of Tecnology, Allahabad, India in 2017 in Power Electronics and Drives. She is currently serving in Madhya Pradesh Public Works Department as Project Engineer. Her areas of interest are power electronic converters and renewable energy based distributed power generation. 


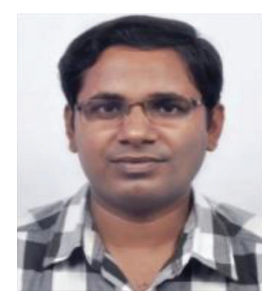

Akhilesh Kumar Gupta is born in Uttar Pradesh, India, in 1982. He received his B.Tech. degree in Electronics and Communication Engineering from BIET, Jhansi, India, in 2007 and M.Tech. degree in Power Electronics and ASIC Design from the Department of Electrical Engineering, M. N. National Institute of Technology (MNNIT), Allahabad, India, in 2013. Presently, he is Research Scholar in the Department of Electrical Engineering at the MNNIT, Allahabad, India.

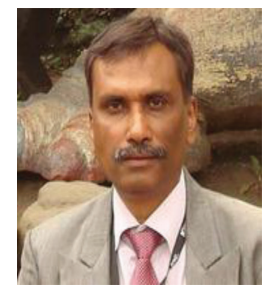

Paulson Samuel is an Associate Professor in the Department of Electrical Engineering M. N. National Institute of Technology (MNNIT), Allahabad, India. From 1984 to 1990 he served as Engineer in the NTPC, New Delhi, and from 1990 onwards as a faculty member at Department of Electrical Engineering, MNNIT, Allahabad. He has completed his Masters Degree in Computer Science and Engineering from MNNIT, Allahabad in 1998 and doctorate degree in Electrical Engineering Department from MNNIT, Allahabad, in 2013. His interests include Power Quality, Distributed Generation and Automation; Control of Power Converters and Multilevel Inverters. 